\title{
ANÁLISE DOS ENCONTROS DE MARKETING DA ASSOCIAÇÃO NACIONAL DE PÓS-GRADUAÇÃO EM ADMINISTRAÇÃO: UM ESTUDO BIBLIOMÉTRICO DA PRODUÇÃO CIENTÍFICA DE MARKETING NO BRASIL
}

\author{
SCIENTIFIC RESEARCH OF MARKETING AREA IN BRAZIL: A BIBLIOMETRIC STUDY OF \\ PROCCEDINGS OF MEETINGS OF THE MARKETING ANPAD
}

\section{Jussara Goulart da Silva}

Mestre em Administração, Doutoranda em Administração na Universidade Nove de Julho. Universidade Federal de Uberlândia, Brasil

\section{Evandro Luiz Lopes}

Doutor e Mestre em Administração (Marketing) pela Universidade Nove de Julho. PPGA -

Universidade Nove de Julho e EPPEN - Universidade Federal de São Paulo, Brasil
Data de recebimento: $11 / 11 / 2016$ Data de aceite: 12/03/2017

\section{RESUMO}

O propósito central deste estudo é identificar o perfil da produção acadêmica das publicações que constituem os anais do Encontro de Marketing da Associação Nacional de Pós-graduação em Administração (EMAVANPAD-Brasil). Para isso, realizamos um estudo bibliométrico que teve como amostra os 633 artigos aprovados nas seis edições do encontro, que aconteceram entre 2004 e 2014. Identificamos os autores mais produtivos assim como as instituições de ensino que mais povoaram as edições do evento. Identificamos também os trabalhos mais citados pelos autores e os trabalhos veiculados no EMA, que tiveram os maiores impactos acadêmicos. Analisamos, por meio da análise fatorial exploratória, a matriz de citações dos 633 artigos e identificamos uma razoável concentração em torno de quatro campos teóricos principais (consumer psychology, consumer behavior, consumer culture theory e Marketing de Serviços).

Palavras-chave: Marketing. Bibliometria. EMA.

\section{ABSTRACT}

The central purpose of this study is to identify the profile of the academic production of the publications that make up the annals of Marketing Meeting ANPAD (EMA). For this, we performed a bibliometric study was to sample the 739 articles approved in the seven editions of the meeting, which took place between 2004 and 2016. We identify the most productive authors as well as educational institutions that more populated editions of the event. We also identify the most cited work by the authors and the works published in the EMA, which had the highest academic impact. Analyzed through the exploratory factor analysis, the matrix of citations of articles 739 and identify a reasonable concentration around four main theoretical fields (consumer psychology, consumer behavior, consumer culture theory and Marketing Services).

Keywords: Marketing. Bibliometrics. EMA. 


\section{INTRODUÇÃO}

Ao refletir sobre as publicações na área de Marketing, logo se percebem as diversas mudanças que vem ocorrendo nas pesquisas mercadológicas. A área agregou diversas subáreas, possibilitando maior contribuição acadêmica, por meio da interdisciplinaridade, e impulsionando a geração de conhecimento, por meio das discussões teóricas e também das constatações empíricas.

Os resultados dessas discussões são publicados nos eventos científicos, tais como congressos, palestras, seminários, painéis, entre outros. Tais encontros permitem que pesquisadores, professores, alunos e profissionais da área possam divulgar suas pesquisas, expressando suas opiniões. Nesses fóruns, os trabalhos são analisados criticamente, possibilitando a interação entre autores e pesquisadores, de forma a garantir o livre debate de ideias e o fortalecimento do desenvolvimento do conhecimento científico (Spiter, Rosa, \& Borba, 2012).

Dentro da área de Marketing, um dos congressos brasileiros de maior prestígio é o Encontro de Marketing da ANPAD. O EMA, como é conhecido, é um evento organizado pela Associação Nacional de Pós-Graduação em Administração (ANPAD-Brasil), que abre oportunidade para que os acadêmicos da área possam divulgar e discutir seus trabalhos junto aos seus pares. O evento, que ocorre a cada dois anos, propõe um espaço de discussão dos temas relevantes, com a finalidade de fomentar o desenvolvimento das áreas de estudo em Marketing, aceitando artigos teóricos, empíricos e relatos técnicos distribuídos em dez temas de interesse específicos.

Neste contexto, o objetivo central desse estudo é identificar o perfil da produção acadêmica das publicações dos anais do EMA. Para tanto, realizou-se um levantamento bibliométrico, analisando-se todos os artigos aprovados nas seis edições do EMA, realizadas entre 2004 e 2014.

Justifica-se a realização deste estudo por conta da relevância que o congresso exerce no desenvolvimento cientifico da área. Outra justificativa é a crescente demanda pela mensuração da produção científica, na qual se pretende conhecer, por meio do mapeando e das revisões sistemáticas, os trabalhos acadêmicos publicados em determinada área, propondo a reflexão acerca dos caminhos futuros da pesquisa científica na área em questão (Cardoso et al., 2005).

Este trabalho está dividido em outras quatro partes, além desta breve introdução. A segunda parte discorre sobre o Marketing na Academia Brasileira e sobre a História do Encontro de Marketing da ANPAD - EMA. Em seguida estão descritos os procedimentos metodológicos utilizados, apresentando os critérios adotados. Na quarta parte, os autores propõem a discussão dos resultados observados e, finalmente, a última seção apresenta as considerações finais a respeito do trabalho realizado.

\section{MARKETING NA ACADEMIA BRASILEIRA}

Desde a implantação da disciplina de Marketing na matriz curricular dos cursos de administração no Brasil, uma questão é continuamente o centro de debates entre professores e pesquisadores: qual a melhor forma de difundir os conhecimentos da área? Mesmo existindo um acervo considerável de pesquisas em Marketing, ainda mais levando-se em conta que seu surgimento no país 
data da década de 1950, poucos trabalhos da área são efetivamente utilizados para apoiar o fortalecimento das bases teóricas e das práticas de gestão (Richers, 1994). Esse fenômeno faz com que a produção nacional em Marketing seja pouco citada pelos pesquisadores da área.

Mesmo que exista certa assimetria entre a opinião dos estudiosos de Marketing acerca da relevância e da validade externa das pesquisas desenvolvidas, há um relativo consenso sobre a existência de um gap entre a teoria e a prática (PRINGLE, 2001). Para muitos, esse gap é potencializado pela falta de dados e de problemas reais para análise, pela falta de recursos para pesquisa, pela dificuldade de validação dos resultados encontrados, pela dificuldade em estabelecer interação com os gestores e praticantes, pela incapacidade de experimentar diretamente os fenômenos e pela dificuldade em se detectar rapidamente as mudanças do ambiente (BRENNAN, 2004; HANSOTIA, 2003; HUNT, 2002; PRINGLE, 2001).

Outra vertente dessa problemática é a falta de desenvolvimento teórico proposto pelos trabalhos nacionais em Marketing. Mesmo que os programas de pós-graduação estejam buscando a internacionalização de sua produção científica, a constatação da deficiência de avanço teórico é bastante saliente, sobretudo em Marketing. Como exemplo, Kovacs et al. (2004, p.13) concluíram que "apesar das pesquisas contemporâneas de marketing estarem focalizadas nas suas diversas áreas, percebemos que apenas uma pequena parte delas parece estar centrada no desenvolvimento de teorias".

Uma análise realizada nas ementas das disciplinas de Marketing ofertadas pelos programas stricto sensu de administração brasileiros (para de- talhes, veja OLIVEIRA; QUINTÃO; URDAN, 2014) revelou a falta de enfoque dada aos periódicos teóricos da área. Os autores do estudo recomendaram uma reflexão acerca, buscando propor aos mestrandos e doutorandos maior contato com o estado da arte da pesquisa na área.

Uma forma de superar os obstáculos que cercam o desenvolvimento científico em Marketing seria a maior sinergia entre os pares, quer seja em grupos de pesquisa, discussões ou simpósios, e também a análise crítica dos estudos elaborados, proporcionada pelos congressos científicos temáticos (GARRAFA, 2009). Sobre esse último aspecto, estudo anterior indicou que a publicação cientifica em Marketing no Brasil surgiu por volta dos anos de 1990 (VIEIRA, 2002) por meio dos Anais do Encontro Anual da Associação Nacional dos Programas de Pós-Graduação em Administração (ENANPAD), da Revista de Administração (RAUSP) e da Revista de Administração de Empresas (RAE), que abriram, entre suas diversas áreas temáticas, espaço para a divulgação da pesquisa científica em Marketing. Contudo, foi em 2004 que a ANPAD instituiu um congresso científico temático - o EMA - específico para esse fim.

Baseados nas produções científicas da área de Marketing, Faria et. al. (2006) observaram a questão da baixa diversidade temática dos trabaIhos, que estão concentrados em poucas áreas de estudo, principalmente a do comportamento do consumidor e da administração de Marketing. Já o estudo desenvolvido por Vieira et al. (2002, p. 2) demonstrou que "a produção nacional reproduz as oscilações e os modismos de inspiração quase que exclusivamente norte-americana". Corroborando isso, Faria (2004, p. 2) também afirmou que "a pro- 
dução acadêmica em marketing no Brasil ainda é majoritariamente subordinada ao que é produzido nos EUA".

Mazzon e Hernandez (2013), ao analisar a produção científica brasileira em Marketing, no período compreendido entre 2000 e 2009, perceberam que a maior fragilidade está na falta de inovação, principalmente no que tange aos procedimentos metodológicos, e sugeriram que os autores e as instituições de ensino superior alavanquem a qualidade da produção de Marketing brasileira. Essa preocupação reforça a importância da iniciativa da ANPAD em institucionalizar o EMA como um dos principais espaços para a discussão do avanço da pesquisa em Marketing no Brasil.

\subsection{HISTÓRIA DO ENCONTRO DE MARKETING DA ANPAD - EMA}

Um grupo de acadêmicos da área de marketing iniciou em janeiro de 2004 a Divisão de Marketing da ANPAD, tendo como objetivo central promover o intercâmbio de ideias e a divulgação da produção científica na área de Marketing. A preocupação principal do grupo foi discutir as condições e perspectivas do campo de estudos em Marketing nos cenários nacional e internacional. Surge desta divisão a proposta do EMA - Encontro de Marketing da ANPAD.

A idealização do EMA foi coordenada por um grupo de pesquisadores da Universidade Federal do Rio Grande do Sul (UFRGS). A concepção inicial do evento entendia que os participantes, tanto acadêmicos quanto profissionais, poderiam inscrever seus trabalhos em dez áreas temáticas propos- tas, que seriam avaliados pelo sistema double blind review. A composição da comissão organizadora foi formada por acadêmicos vinculados aos programas pós-graduação stricto sensu em Administração no país e a coordenação geral do primeiro EMA foi realizada pelos professores Carlos Alberto Vargas Rossi e Fernando Bins Luce, ambos da UFRGS.

Em novembro de 2004, aconteceu em Curitiba a primeira edição do EMA. No evento, foi oferecido o prêmio "Raimar Richers" aos autores do melhor trabalho submetido ao encontro. O nome do prêmio foi uma homenagem à inestimável contribuição daquele acadêmico ao desenvolvimento da área de Marketing no Brasil. O comitê instituiu a inovação, o rigor metodológico e o potencial de contribuição para o avanço do conhecimento em Marketing como critérios para conceder a premiação.

Foram submetidos 356 trabalhos ao evento, dos quais 60 foram aprovados. O artigo que recebeu o prêmio Raimar Richers é intitulado "Elementos Formadores de Preferências no Ambiente da Internet", cujos autores são os professores George Bedinelli, Reynaldo Cavalheiro Marcondes e Silvio. O prêmio foi entregue pelo presidente da ANPAD na época, o saudoso Professor Clóvis L. Machado-da-Silva.

Percebendo a relevância e o impacto do primeiro evento, a comissão organizadora definiu que o Encontro de Marketing aconteceria a cada dois anos, e planejou o segundo encontro, que ocorreu em maio de 2006, na cidade do Rio de Janeiro, sob a coordenação geral do Professor Marcos Cortez Campomar da Universidade de São Paulo.

Foram submetidos 415 trabalhos ao II EMA, sendo 125 aprovados, porém apenas 124 
trabalhos foram inscritos e apresentados. As submissões foram distribuídas em três áreas temáticas propostas, tendo sido premiado o artigo "Redes Sociais e o Marketing de Inovações" dos autores Herbert Kimura, Diógenes Manoel Leiva Martin e Leonardo Fernando Cruz Basso da Universidade Presbiteriana Mackenzie.

A cidade de Curitiba foi escolhida sediar o III EMA em 2008. Dado o amadurecimento do congresso, algumas mudanças foram implementadas em seu formato. A avaliação dos trabalhos foi no mesmo sistema blind review, porém em dois estágios, tendo sido avaliados inicialmente os resumos expandidos. Em um segundo momento, os autores com resumos aprovados deveriam submeter os trabalhos completos. Os artigos poderiam ser submetidos para sessões de dois formatos: para as sessões chamadas de competitivas e para as sessões especiais temáticas. A coordenação do evento foi novamente do Prof. Carlos Alberto Vargas Rossi da UFRGS. Essa edição do evento contou com 459 trabalhos submetidos, dos quais 143 foram aprovados e inscritos no evento. O prêmio de melhor artigo foi conferido ao trabalho intitulado The Relationship between Market Orientation and Business Performance: a Brazilian Meta-Analysis, do Prof. Valter Afonso Vieira da Universidade Estadual de Maringá.

O IV EMA aconteceu em 2010 na cidade de Florianópolis (SC) e foi coordenado pelo Prof. Eduardo André Teixeira Ayrosa. Naquele ano, os artigos que foram mais bem avaliados receberam avaliação em regime de fast track para serem considerados na pauta editorial de periódicos acadêmicos, com classificação no sistema de Qualis/CAPES no estrato B2 ou superior. A demais, houve a inclu- são do tracking "Tema Livre" para os trabalhos que não se enquadravam nas diversas áreas temáticas do evento. Nessa edição, foram submetidos 417 artigos, sendo 99 aprovados. $O$ artigo premiado foi desenvolvido por Flávia Zimmerle da Nóbrega Costa e por André Luiz Maranhão de Souza Leão (Universidade Federal de Pernambuco), tendo como título "Formações Discursivas de uma Marca Global num Contexto Local: um Estudo Foto Etnográfico da Presença Imagética da Coca-Cola numa Grande Região Metropolitana Brasileira, Inspirado no Método Arqueológico de Michel Foucault".

Foi novamente em Curitiba (PR), no ano de 2012, que ocorreu o V EMA, sob a coordenação do Prof. José Mauro da Costa Hernandez, do Centro Universitário FEI e EACH-USP. Um total de 376 trabalhos foram submetidos, tendo sido aprovados 108 artigos. O trabalho que recebeu a premiação tem como título A New Conceptual Model for Business Ecosystem Visualization and Analysis: an Empirical Test in the Videogame Industry, cujos autores são Luiz Felipe Hupsel Vaz, Antonio Roberto Ramos Nogueira, Marco Aurelio de Souza Rodrigues e Paula Castro Pires de Souza Chimenti da Universidade Federal do Rio de Janeiro.

Finalmente, a mais recente edição do Encontro de Marketing da ANPAD (VI EMA) aconteceu em 2014 em Gramado (RS). Naquele ano, a Divisão de Marketing, juntamente com a ReMark (Revista Brasileira de Marketing) e com a PKMT (Revista Brasileira de Pesquisa de Mercado, Opinião e Mídia), preparou uma edição especial com os melhores trabalhos apresentados no evento. A coordenação do evento ficou por conta do Prof. Paulo Henrique Muller Prado da Universidade Federal do Paraná. Foram aprovados 99 artigos, 
dentre os 418 submetidos às 10 áreas temáticas.

O artigo premiado tem como título The Effects of Trust Transference, Mobile Attributes and Enjoyment on Mobile Trust, de autoria de Cristiane Junqueira Giovannini e de Jorge Brantes Ferreira da PUC/RJ.
O Encontro de Marketing da ANPAD - EMA é uma troca de conhecimentos enriquecedor para grupos e pesquisadores da área. No ano de 2016, o evento contará com a sua sétima edição, que será realizada na cidade de Belo Horizonte/MG. A Tabela 1 apresenta sinteticamente os dados das edições do encontro.

Tabela 1 - Dados resumidos dos Encontros de Marketing da ANPAD (2004-2014)

\begin{tabular}{|c|c|c|c|c|c|c|}
\hline Edição & Ano & Local & Coordenador(es) & Submissões (n) & $\begin{array}{l}\text { Aprovados } \\
\text { (n) }\end{array}$ & $\begin{array}{c}\text { Taxa de } \\
\text { aprovação } \\
(\%)\end{array}$ \\
\hline $1 a$. & 2004 & Curitiba (PR) & $\begin{array}{c}\text { Carlos Alberto } \\
\text { Vargas Rossi e } \\
\text { Fernando Bins Luce }\end{array}$ & 356 & 60 & $16.9 \%$ \\
\hline $2 a$. & 2006 & $\begin{array}{c}\text { Rio de Janeiro } \\
\text { (RJ) }\end{array}$ & $\begin{array}{c}\text { Marcos Cortez } \\
\text { Campomar }\end{array}$ & 415 & 124 & $29.9 \%$ \\
\hline $3 a$. & 2008 & Curitiba (PR) & $\begin{array}{l}\text { Carlos Alberto } \\
\text { Vargas Rossi }\end{array}$ & 459 & 143 & $31.2 \%$ \\
\hline $4 a$. & 2010 & $\begin{array}{l}\text { Florianópolis } \\
\qquad(\mathrm{SC})\end{array}$ & $\begin{array}{l}\text { Eduardo André } \\
\text { Teixeira Ayrosa }\end{array}$ & 417 & 99 & $23.7 \%$ \\
\hline $5 a$. & 2012 & Curitiba (PR) & $\begin{array}{l}\text { José Mauro da } \\
\text { Costa Hernandez }\end{array}$ & 376 & 108 & $28.7 \%$ \\
\hline 6a. & 2014 & Gramado (RS) & $\begin{array}{c}\text { Paulo Henrique } \\
\text { Muller Prado }\end{array}$ & 418 & 99 & $23.7 \%$ \\
\hline & & Total & & 2.442 & 633 & $25.9 \%$ \\
\hline
\end{tabular}

Fonte: autores.

\section{PROCEDIMENTOS METODOLÓGICOS}

Para atingir o objetivo central dessa pesquisa, realizamos um levantamento bibliométrico, no qual foram descritos e analisados os trabalhos aprovados nos Encontros de Marketing da ANPAD, que aconteceram entre os anos de 2004 e 2014. A análise bibliométrica é utilizada para apontar rumos a novos estudos ou direcioná-los com maior precisão, mitigando a margem de risco na tomada de decisão em pesquisar determinado assunto, por parte do pesquisador (MACEDO; BOTELHO; DUARTE, 2010)

Considerando o objetivo proposto, o procedimento metodológico refere-se a uma pesquisa bibliográfica de abordagem quantitativa e classificada como descritiva. O levantamento em questão abrangeu amostra significativa composta pelas 
versões completas dos artigos nos anais do EMA, que foram aprovados e apresentados entre 2004 e 2014. Essa coleta identificou 633 artigos, sendo que a busca para composição do banco de dados foi realizada por meio dos CDs dos anais do EMA e também por meio do portal da ANPAD.

Inicialmente, realizou-se a leitura dos títulos e resumos dos trabalhos, qualificando-os e categorizando-os em uma planilha com os seus dados descritivos, para posterior análise.

As informações de cada artigo foram coletadas e classificadas nos seguintes grupos:

a. Aspectos Gerais da produção acadêmica em Marketing: número de artigos por ano, com as submissões e número de aprovações, além do idioma;

b. Perfil dos Autores: nome do autor, gênero, filiação, número de autores, instituições envolvidas, considerando-se apenas a primeira filiação do autor;

c. Tema do artigo: os trabalhos foram classificados por temática de pesquisa. Contudo, os artigos publicados nas edições do EMA de 2004 e 2008 não foram computados, devido à metodologia aplicada aos dois congressos;

d. Natureza da Pesquisa: tipificação do método utilizado na condução das pesquisas e também a natura das unidades amostrais.
Além da categorização, realizada por meio da análise dos dados descritivos, realizou-se também a análise fatorial exploratória (AFE) da matriz de citações dos artigos, com o objetivo de mapear os principais campos teóricos tratados nos artigos apresentados nos encontros. A AFE deu-se pelo método de análise de componentes principais e rotação ortogonal Varimax (HAIR et al., 2006). Os seguintes critérios foram adotados para a AFE: comunalidade extraída dos itens $\left(h^{2}\right)$ superior a 0,5, teste de esfericidade de Bartlett significativo ao nível de $5 \%$ e teste Kaiser-Meyer-Olkin (KMO) superior a 0,7 (HAIR et al., 2006). Para essa etapa, utilizou-se o software SPSS for Windows versão 18.0.

\subsection{ASPECTOS GERAIS DA PRODUÇÃO ACADÊMICA EM MARKETING}

As análises foram realizadas com base nos artigos publicados nos Encontros de Marketing da ANPAD. Inicialmente, mapeou-se a evolução temporal dos artigos do período de 2004 a 2014. A Tabela 2 apresenta os dados referentes ao número de artigos analisados por ano, perfazendo um total de 633 publicados, de um total de 2.441 submetidos. A edição do ano de 2008 apresentou o maior número de submissões, 459 (18,8\%), e também o maior número de artigos aprovados, $143(22,6 \%$ do total com uma taxa de aprovação de 31,2\%). Cerca de $26 \%$ dos trabalhos submetidos ao EMA foram aprovados para publicação e apresentação.

Tabela 2 - Número de artigos analisados por ano

\begin{tabular}{ccccccc} 
Edição & $\begin{array}{c}\text { Submetidos } \\
\text { (n) }\end{array}$ & $\begin{array}{c}\text { Submetidos } \\
(\mathbf{( \% )}\end{array}$ & $\begin{array}{c}\text { Aprovados } \\
\text { (n) }\end{array}$ & $\begin{array}{c}\text { Aprovados } \\
(\% \text { do total) }\end{array}$ & $\begin{array}{c}\text { Aprovados } \\
\text { (\% da } \\
\text { edição) }\end{array}$ & $\begin{array}{c}\text { Artigos } \\
\text { em língua } \\
\text { estrangeira } \\
\text { (n) }\end{array}$ \\
\hline 2004 & 356 & 14,6 & 60 & $9.5 \%$ & $16.9 \%$ & 3 \\
\hline 2006 & 415 & 17,0 & 124 & $19.6 \%$ & $29.9 \%$ & 4 \\
\hline
\end{tabular}




\begin{tabular}{ccccccc}
\hline 2008 & 459 & 18,8 & 143 & $22.6 \%$ & $31.2 \%$ & 7 \\
\hline 2010 & 417 & 17,1 & 99 & $15.6 \%$ & $23.7 \%$ & 10 \\
\hline 2012 & 376 & 15,4 & 108 & $17.1 \%$ & $28.7 \%$ & 3 \\
\hline 2014 & 418 & 17,1 & 99 & $15.6 \%$ & $23.7 \%$ & 2 \\
\hline Total & 2441 & 100,0 & 633 & $100.0 \%$ & $25.9 \%$ & 29 \\
\hline Média & 407 & 100,0 & 106 & $16.7 \%$ & $25.9 \%$ & 5 \\
\hline
\end{tabular}

Fonte: autores.

Destacamos o esforço dos autores em submeter artigos em outro idioma. Dos 29 artigos em língua estrangeira (1,2\% do total de submissões), apenas um foi em espanhol (em 2006) e o restante em inglês.

A IES que mais aprovou artigos em outro idioma no período analisado foi a Fundação Getulio Vargas com 4 trabalhos $(13,79 \%)$, seguida da Universidade de São Paulo (USP), do Insper, da Universidade do Vale do Rio dos Sinos e da Universidade Estadual de Maringá que apresentaram 3 artigos cada (10,34\%).

\subsection{PERFIL DOS AUTORES}

A Tabela 3 apresenta a quantidade de autores por artigo. Nota-se certa concentração na produção científica realizada por dois autores (40\% do total). Trabalhos individuais somaram $12,5 \%$ do total $(n=79)$, enquanto trabalhos com cinco ou mais autores representaram pouco mais de $6 \%$ do total $(n=39$; $6,1 \%)$.

Tabela 3 - Número de Autores por artigo

\begin{tabular}{cccc} 
Número de Autores & $\mathbf{n}$ & $\mathbf{\%}$ & \% acumulado \\
\hline 1 & 79 & 12,5 & 12,5 \\
\hline 2 & 253 & 40,0 & 52,5 \\
\hline 3 & 184 & 29,1 & 81,5 \\
\hline 4 & 78 & 12,3 & 93,8 \\
\hline 5 & 28 & 4,4 & 98,3 \\
\hline 6 & 11 & 1,7 & 100,0 \\
\hline Total & 633 & 100 & \\
\hline
\end{tabular}

Fonte: autores.

Analisando o perfil do primeiro autor de cada um dos 633 artigos dos Anais, constata-se que a maioria é do sexo masculino. Contudo, a participação das mulheres como primeira autoria nos trabalhos de Marketing vem crescendo, quando se comparam os dados das primeiras edições (2004: $n=20 ; 33,3 \%$ e 2008: $n=45 ; 36,3 \%)$ e média dos eventos $\left(M_{\text {total }}=44,5 \%\right)$. 
Tabela 4 - Gênero do primeiro autor por ano

\begin{tabular}{ccccc} 
Ano & Feminino (n) & \% & Masculino (n) & \% \\
\hline 2004 & 20 & 33,3 & 40 & 66,7 \\
\hline 2006 & 45 & 36,3 & 79 & 63,7 \\
\hline 2008 & 60 & 42,0 & 83 & 58,0 \\
\hline 2010 & 47 & 47,5 & 52 & 52,5 \\
\hline 2012 & 61 & 56,5 & 47 & 43,5 \\
\hline 2014 & 49 & 49,5 & 50 & 50,5 \\
\hline Total & 282 & 44,5 & 351 & 55,5 \\
\hline
\end{tabular}

Fonte: autores.

Ainda analisando o primeiro autor de cada trabalho, identificamos que o pesquisador mais produtivo do congresso no período verificado (2004-2014) é o Prof. Valter Afonso Vieira da Universidade Estadual de Maringá. O Prof. Valter teve 6 artigos (0,9\% do total) publicados.
Em seguida, os Professores André Luiz Maranhão de Souza Leão, Evandro Luiz Lopes e Wagner Junior Ladeira desenvolveram e publicaram 5 artigos cada (0,8\%). A Tabela 5 mostra a classificação e a quantidade de artigos publicados dos autores mais produtivos.

Tabela 5 - Autores mais produtivos do EMA (primeiro autor do artigo)

\section{Autor}

\begin{tabular}{l} 
Valter Afonso Vieira \\
\hline André Luis M. de S. Leão \\
\hline Evandro Luiz Lopes \\
\hline Wagner Junior Ladeira \\
\hline Alexandre Faria
\end{tabular}

Carlos Alberto Vargas Rossi

Celso Augusto de Matos

Fabiano Larentis

Lelis Balestrin Espartel

Marlon Dalmoro

Marta Olivia R. de Oliveira

Plínio Rafael Reis Monteiro

Rosana Vieira de Souza

Salomão Alencar de Farias

Vivian lara Strehlau

Fonte: autores.

Nota. Fonte: primeiros autores dos trabalhos apresentados no EMA

A análise da produtividade dos autores, sem considerar a posição na linha de coautoria, revela que o Prof. Fernando Bins Luce é o pesqui-

Papers publicados

$\%$ do Total

\begin{tabular}{ll}
6 & 0,9 \\
\hline 5 & 0,8 \\
\hline 5 & 0,8 \\
5 & 0,8 \\
\hline 4 & 0,6 \\
\hline 4 & 0,6 \\
\hline 4 & 0,6 \\
\hline 4 & 0,6 \\
\hline 4 & 0,6 \\
\hline 4 & 0,6 \\
\hline 4 & 0,6 \\
\hline 4 & 0,6 \\
\hline 4 & 0,6 \\
\hline 4 & 0,6 \\
\hline
\end{tabular}


Augusto de Matos, Jorge Ferreira da Silva, Maria de Lourdes de Azevedo Barbosa e Paulo Henrique
Muller Prado, todos com 10 trabalhos aprovados. A Tabela 6 elenca os pesquisadores mais produtivos.

Tabela 6 - Autores mais produtivos do EMA

\begin{tabular}{|c|c|c|}
\hline Autor & Papers publicados & $\%$ do Total \\
\hline Fernando Bins Luce & 11 & 0,3 \\
\hline Celso Augusto de Matos & 10 & 0,3 \\
\hline Jorge Ferreira da Silva & 10 & 0,3 \\
\hline Maria de Lourdes de Azevedo Barbosa & 10 & 0,3 \\
\hline Paulo Henrique Muller Prado & 10 & 0,3 \\
\hline Rita de Cássia de Faria Pereira & 10 & 0,3 \\
\hline Cristiane Pizzutti dos Santos & 9 & 0,2 \\
\hline Evandro Luiz Lopes & 9 & 0,2 \\
\hline Lelis Balestrin Espartel & 9 & 0,2 \\
\hline Marcelo Gattermann Perin & 8 & 0,2 \\
\hline Marta Olivia Rovedder de Oliveira & 8 & 0,2 \\
\hline Valter Afonso Vieira & 8 & 0,2 \\
\hline Victor Manoel Cunha de Almeida & 8 & 0,2 \\
\hline Vivian lara Strehlau & 8 & 0,2 \\
\hline
\end{tabular}

Fonte: autores.

Buscando identificar o impacto dos artigos publicados no Encontro de Marketing da ANPAD, utilizamos o software Harzing's Publish or Perish. O resultado indicou os artigos do congresso com maior número de citações. Apenas 111 artigos $(17,5 \%$ do total) receberam citações posteriores à sua publicação. Esse tímido resultado pode ser um sinal da baixa inovação apresenta pelos estudos acadêmicos em Marketing e/ou da falta de valori- zação da produção acadêmica nacional por parte dos próprios pesquisadores da área.

O trabalho mais citado ( $n=25$ citações; 2,5 citações/ano) foi o artigo desenvolvido por Carla Barros intitulado "A invisibilidade do mercado de baixa renda nas pesquisas de marketing: as camadas populares consomem ou sobrevivem?", que foi apresentado no EMA-2006. A Tabela 7 apresenta os trabalhos mais citados.

Tabela 7 - Artigos mais referenciados

\section{Autores}

Título do Artigo
Ano Citações (n)

Citações/

ano

A "Invisibilidade" do Mercado de Baixa

Carla Barros

\section{6}

Renda nas Pesquisas de Marketing: as Camadas Populares Consomem ou Sobrevivem? 


\begin{tabular}{|c|c|c|c|c|}
\hline $\begin{array}{l}\text { Josmar Andrade, José } \\
\text { Afonso Mazzon e Sérgio } \\
\text { Katz }\end{array}$ & $\begin{array}{l}\text { Boca-a-Boca Eletrônico: Explorando } \\
\text { e Integrando Conceitos de Marketing } \\
\text { Viral, Buzz Marketing e Word-of-Mouse }\end{array}$ & 2006 & 18 & 1,80 \\
\hline $\begin{array}{l}\text { Isabel Balloussier } \\
\text { Cerchiaro, João Felipe } \\
\text { Rammelt Sauerbronn e } \\
\text { Eduardo André Teixeira } \\
\text { Ayrosa }\end{array}$ & $\begin{array}{l}\text { Uma Visão Alternativa da Pesquisa em } \\
\text { Marketing: Como a Fenomenologia } \\
\text { Pode Contribuir para Gerar } \\
\text { Conhecimento de Marketing }\end{array}$ & 2004 & 18 & 1,50 \\
\hline $\begin{array}{l}\text { Daiane Scaraboto, } \\
\text { Fernanda Pagliarini } \\
\text { Zilles, Jorgelina Beltrán } \\
\text { Rodriguez e Márcio André } \\
\text { Kny }\end{array}$ & $\begin{array}{l}\text { Pequenos Luxos, Grandes Prazeres - } \\
\text { Significados do Consumo e Valores dos } \\
\text { Consumidores de Joalheria e Vestuário } \\
\text { de Luxo }\end{array}$ & 2006 & 17 & 1,70 \\
\hline Salomão Alencar de Farias & $\begin{array}{l}\text { Em Busca da Inovação no Marketing } \\
\text { Brasileiro: Discutindo o Processo de } \\
\text { Publicação de Artigos em Revistas e } \\
\text { Congressos }\end{array}$ & 2004 & 15 & 1,25 \\
\hline Rafael Zunino & $\begin{array}{l}\text { Comportamento de Compra de } \\
\text { Torcedores de Clubes de Futebol: Um } \\
\text { Estudo da Aquisição de Produtos dos } \\
\text { Patrocinadores }\end{array}$ & 2006 & 14 & 1,40 \\
\hline Leticia Moreira Casotti & $\begin{array}{l}\text { Como Enxergar Diferenças no } \\
\text { Comportamento do Consumidor? } \\
\text { Algumas Reflexões sobre os Caminhos } \\
\text { do Marketing }\end{array}$ & 2004 & 14 & 1,17 \\
\hline $\begin{array}{l}\text { Paulo H. M. Prado e } \\
\text { Rubens da Costa Santos }\end{array}$ & $\begin{array}{l}\text { Satisfação, Qualidade no } \\
\text { Relacionamento e Lealdade entre } \\
\text { Clientes e Bancos de Varejo }\end{array}$ & 2004 & 14 & 1,17 \\
\hline $\begin{array}{l}\text { Michelle Helena Kovacs, } \\
\text { André L. Maranhão de } \\
\text { Souza Leão, Ricardo S. } \\
\text { Gomes Vieira, Lourdes } \\
\text { Barbosa e Cecília de Melo } \\
\text { Dias }\end{array}$ & $\begin{array}{l}\text { Podemos Confiar nos Resultados de } \\
\text { Nossas Pesquisas? Uma Avaliação } \\
\text { dos Procedimentos Metodológicos nos } \\
\text { Artigos de Marketing do EnANPAD }\end{array}$ & 2004 & 12 & 1,00 \\
\hline $\begin{array}{l}\text { Alcívio Vargas Neto e } \\
\text { Fernando Bins Luce }\end{array}$ & $\begin{array}{l}\text { Mensuração de Brand Equity baseado } \\
\text { no consumidor: avaliação de escala } \\
\text { multidimensional }\end{array}$ & 2006 & 11 & 1,10 \\
\hline
\end{tabular}

Fonte: autores.

Nota. Fonte: Harzing's Publish or Perish 


\subsection{PRODUTIVIDADE DAS INSTITUIÇÕES DE ENSINO}

Analisando-se a produtividade das instituições de ensino, nota-se que a Universidade de São Paulo ocupa a primeira posição, com um total de 41 (6,5\% do total) trabalhos publicados. Em segundo lugar, apa- rece a Universidade Federal do Rio de Janeiro $(n=36$; 5,7\%). Nesse contexto, ressalta-se a importância das instituições de ensino superior públicas e confessionais, pois das 10 instituições mais produtivas em Marketing no ranking elaborado figura apenas uma instituição de ensino privada (Universidade Nove de Julho). O ranking detalhado é apresentado na Tabela 8.

Tabela 8 - Produtividade por Instituição de Ensino

\begin{tabular}{clcc} 
Ranking & \multicolumn{1}{c}{ Instituição de Ensino } & $\begin{array}{c}\text { Artigos } \\
\text { publicados (n) }\end{array}$ & \% do Total \\
& Universidade de São Paulo (USP) & 41 & 6,5 \\
\hline 2 & Universidade Federal do Rio de Janeiro (UFRJ) & 36 & 5,7 \\
\hline 3 & Fundação Getulio Vargas (FGV) & 35 & 5,5 \\
\hline 4 & Universidade Federal de Pernambuco (UFPE) & 32 & 5,1 \\
\hline 5 & Universidade do Vale do Rio dos Sinos (UNISINOS) & 26 & 4,1 \\
\hline 6 & Universidade Federal do Rio Grande do Sul (UFRGS) & 25 & 3,9 \\
\hline 7 & Universidade Federal do Paraná (UFPR) & 24 & 3,8 \\
\hline 8 & Pontifícia Universidade Católica do Rio de Janeiro (PUC - RJ) & 23 & 3,6 \\
\hline 9 & Universidade Nove de Julho (UNINOVE) & 19 & 3,0 \\
\hline 10 & Pontifícia Universidade Católica do Rio Grande do Sul & 17 & 2,7 \\
\hline
\end{tabular}

Fonte: autores.

\subsection{PREFERÊNCIA PELAS ÁREAS TEMÁTICAS}

A análise da preferência temática dos pesquisadores de Marketing foi parcialmente prejudicada por conta de uma mudança operacional feita nas edições do EMA de 2004 e 2008. Nessas edições, a submissão dos trabalhos $(n=203)$ não foi realizada por área temática, impedindo que essa classificação fosse feita.

O tema de maior interesse de pesquisa foi o Comportamento do Consumidor ( $n=87 ; 13,7 \%$ ). Em nossa classificação, agrupamos os artigos publicados nos temas Comportamento do Consumir I e
II, pois essa diferenciação foi realizada apenas nas últimas edições do evento.

O segundo tema de maior interesse foi Atividades, aplicações e técnicas de Marketing ( $n=49 ; 7,7 \%)$ e, em terceiro, o Dimensionamento e previsão de mercados $(n=36 ; 6 \%)$. Destaca-se que apenas $3(0,5 \%)$ artigos publicados pertencem à linha temática de Contribuições à teoria de Marketing no Brasil e somente 12 trabalhos $(1,9 \%)$ fazem parte do tema Métodos de pesquisa e teoria em Marketing. Esse fenômeno nos permite supor que o problema da falta do avanço teórico na área de Marketing citado por Kovacs et al. (2004) ainda não foi solucionado. O deta- 
Ihamento da preferência temática dos pesquisadores é apresentado na Tabela 9.

Interessante notar que alguns temas são predominantemente pesquisados por homens (Administração do comporto mercadológico= 84,2\%; Métodos de pesquisa e teoria em Marke- ting $=71,4 \%$ e Relacionamento, satisfação e lealdade $=60,8 \%$ ), ao passo que outros temas são pesquisados prioritariamente por pesquisadoras (Cultura e consumo $=80 \%$; Marketing, ambiente, Estado e sociedade $=75 \%$ e Marketing e sociedade $=70 \%)$.

Tabela 9 - Classificação dos Artigos Publicados por áreas temáticas

\begin{tabular}{|c|c|c|c|c|c|}
\hline Temas de Interesse & $\begin{array}{l}\text { Artigos } \\
\text { (n) }\end{array}$ & $\%$ & $\begin{array}{c}\% \\
\text { acum. }\end{array}$ & Masculino* & Feminino* \\
\hline Comportamento do Consumidor I e II & 87 & $13,7 \%$ & $13,7 \%$ & $50,7 \%$ & $49,3 \%$ \\
\hline $\begin{array}{l}\text { Atividades, Aplicações e Técnicas de } \\
\text { Marketing }\end{array}$ & 49 & $7,7 \%$ & $21,5 \%$ & $67,3 \%$ & $32,7 \%$ \\
\hline $\begin{array}{l}\text { Comportamento, Dimensionamento e Previsão } \\
\text { de Mercados }\end{array}$ & 38 & $6,0 \%$ & $27,5 \%$ & $65,8 \%$ & $34,2 \%$ \\
\hline Teorias, Modelos e Metodologia em Marketing & 37 & $5,8 \%$ & $33,3 \%$ & $56,8 \%$ & $43,2 \%$ \\
\hline Cultura e Consumo & 30 & $4,7 \%$ & $38,1 \%$ & $20,0 \%$ & $80,0 \%$ \\
\hline Consumo, Cultura e Grupos Sociais & 23 & $3,6 \%$ & $41,7 \%$ & $34,8 \%$ & $65,2 \%$ \\
\hline $\begin{array}{l}\text { Estratégias de Marketing e Marketing } \\
\text { Internacional }\end{array}$ & 23 & $3,6 \%$ & $45,3 \%$ & $34,8 \%$ & $65,2 \%$ \\
\hline Marketing de Serviços e de Relacionamento & 23 & $3,6 \%$ & $49,0 \%$ & $56,5 \%$ & $43,5 \%$ \\
\hline Marketing e Sociedade & 20 & $3,2 \%$ & $52,1 \%$ & $30,0 \%$ & $70,0 \%$ \\
\hline Administração de Composto de Marketing & 19 & $3,0 \%$ & $55,1 \%$ & $84,2 \%$ & $15,8 \%$ \\
\hline Métodos de Pesquisa e Teoria em Marketing & 12 & $1,9 \%$ & $57,0 \%$ & $71,4 \%$ & $28,6 \%$ \\
\hline Gestão de Produtos, Marcas e Comunicação & 12 & $1,9 \%$ & $58,9 \%$ & $50,0 \%$ & $50,0 \%$ \\
\hline Relacionamentos, Satisfação e Lealdade & 12 & $1,9 \%$ & $60,8 \%$ & $91,7 \%$ & $8,3 \%$ \\
\hline Inovação, Tecnologia e Interatividade & 11 & $1,7 \%$ & $62,6 \%$ & $54,5 \%$ & $45,5 \%$ \\
\hline Marketing, Ambiente, Estado e Sociedade & 8 & $1,3 \%$ & $63,8 \%$ & $25,0 \%$ & $75,0 \%$ \\
\hline $\begin{array}{l}\text { Varejo, Canais de Distribuição e Gestão de } \\
\text { Preços }\end{array}$ & 7 & $1,1 \%$ & $64,9 \%$ & $42,9 \%$ & $57,1 \%$ \\
\hline Gestão do Varejo e da Distribuição & 6 & $0,9 \%$ & $65,9 \%$ & $50,0 \%$ & $50,0 \%$ \\
\hline Escalas, Medidas e Modelos e Previsão & 5 & $0,8 \%$ & $66,7 \%$ & $60,0 \%$ & $40,0 \%$ \\
\hline Contribuições à Teoria de Marketing no Brasil & 3 & $0,5 \%$ & $67,1 \%$ & $100,0 \%$ & $0,0 \%$ \\
\hline Produtividade e Marketing & 3 & $0,5 \%$ & $67,6 \%$ & $66,7 \%$ & $33,3 \%$ \\
\hline Temas Livres & 2 & $0,3 \%$ & $67,9 \%$ & $50,0 \%$ & $50,0 \%$ \\
\hline $\begin{array}{l}\text { Artigos não classificados nos temas (EMAs } \\
2004 \text { e 2008) }\end{array}$ & 203 & $32,1 \%$ & $100,0 \%$ & $60,6 \%$ & $39,4 \%$ \\
\hline Total & 633 & 100,0 & & $55,50 \%$ & $44,50 \%$ \\
\hline
\end{tabular}

Fonte: autores.

Nota. ${ }^{*}$ ) Refere-se ao gênero do primeiro autor do trabalho publicado 


\subsection{ABORDAGEM METODOLÓGICA, FONTE DE DADOS E TÉCNICA DE ANÁLISE DE DADOS}

Com relação à opção pela abordagem metodológica dos trabalhos publicados no evento, há predominância da perspectiva qualitativa ( $n=294$; $46,4 \%)$, em relação aos estudos quantitativos ( $n=258 ; 40,8 \%$ ). As pesquisas que utilizam as duas abordagens metodológicas perfazem o total de 81 trabalhos (12,7\%). A distribuição entre as edições do EMA está apresentada na Tabela 10.

Tabela 10 - Opções metodológicas

\begin{tabular}{llllllll} 
Abordagem & \multicolumn{1}{c}{$\mathbf{2 0 0 4}$} & $\mathbf{2 0 0 6}$ & $\mathbf{2 0 0 8}$ & $\mathbf{2 0 1 0}$ & $\mathbf{2 0 1 2}$ & $\mathbf{2 0 1 4}$ & Total \\
\hline Qualitativa $(\mathrm{n})$ & 23 & 55 & 67 & 57 & 53 & 39 & 294 \\
\hline$\%$ & $38.3 \%$ & $44.4 \%$ & $46.9 \%$ & $57.6 \%$ & $49.1 \%$ & $39.4 \%$ & $46.4 \%$ \\
\hline $\begin{array}{l}\text { Quantitativa } \\
(\mathrm{n})\end{array}$ & 25 & 46 & 52 & 31 & 47 & 57 & 258 \\
\hline$\%$ & $41.7 \%$ & $37.1 \%$ & $36.4 \%$ & $31.3 \%$ & $43.5 \%$ & $57.6 \%$ & $40.8 \%$ \\
\hline Ambas $(\mathrm{n})$ & 12 & 23 & 24 & 11 & 8 & 3 & 81 \\
\hline$\%$ & $20.0 \%$ & $18.5 \%$ & $16.8 \%$ & $11.1 \%$ & $7.4 \%$ & $3.0 \%$ & $12.8 \%$ \\
\hline Total & 60 & 124 & 143 & 99 & 108 & 99 & 633 \\
\hline
\end{tabular}

Fonte: autores.

Ainda sobre a preferência pela abordagem metodológica, aparentemente a opção pela abordagem mista - quali-quanti - está perdendo força, ao passo que a abordagem quantitativa vem ganhando espaço nos últimos anos, como apresentado na Figura 1.

Figura 1 - Opções metodológicas e sua distribuição no tempo

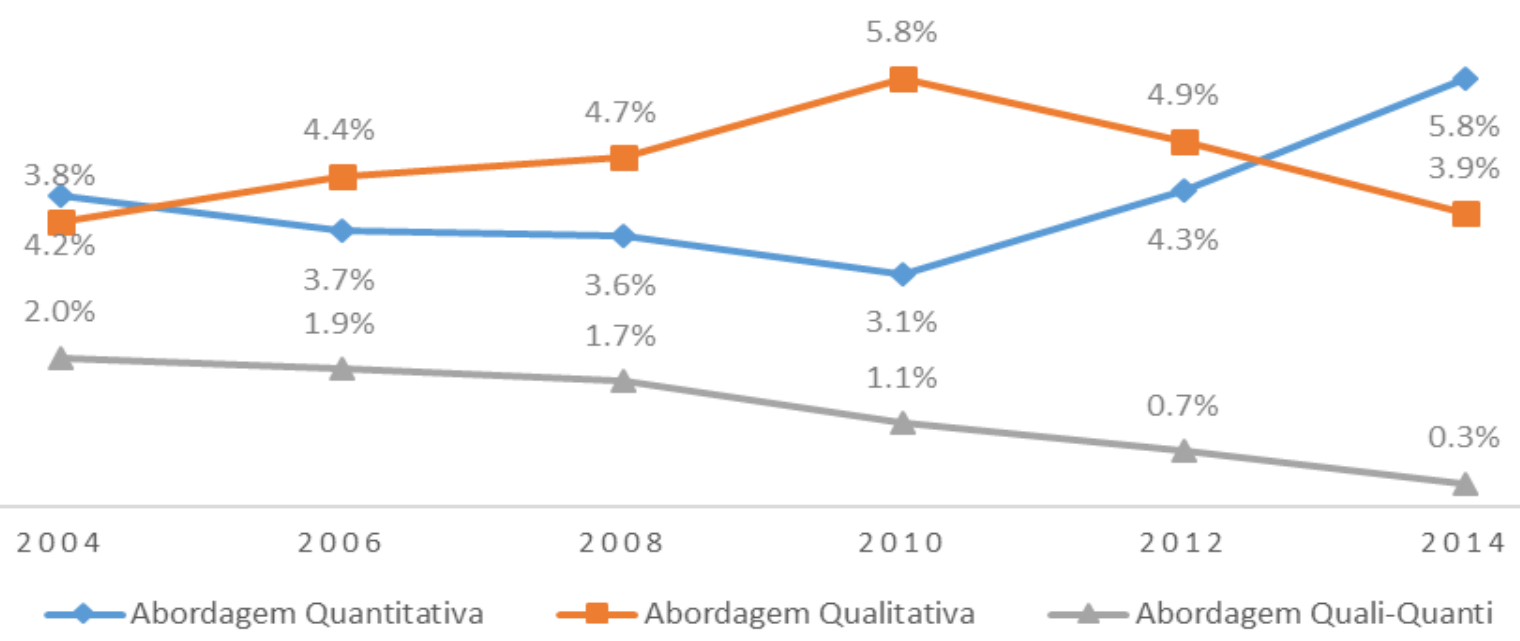

Fonte: autores. 
A maioria dos estudos apresentados no EMA utilizou dados primários ( $n=389 ; 61,5 \%$ ), como apresentado na Tabela 11.

Tabela 11 - Tipo de fonte de dados

\begin{tabular}{lccc}
\multicolumn{1}{c}{ Tipos de Dados } & $\mathbf{n}$ & $\mathbf{\%}$ & \% acumulado \\
\hline Primários & 389 & 61,5 & 86,3 \\
\hline Secundários & 157 & 24,8 & 24,8 \\
\hline Ambos & 87 & 13,7 & 100,0 \\
\hline Total & 633 & 100,0 &
\end{tabular}

Fonte: autores.

A classificação dos artigos quanto à tipificação aponta maior preferência por estudos exploratório $(63,1 \%)$ do que pelos descritivos $(28,3 \%)$ ou pelas pesquisas explicativas $(8,6 \%)$. Os procedi- mentos técnicos mais adotados nos artigos foram o levantamento de campo $(61,6 \%)$, as pesquisas bibliográficas $(14,1 \%)$ e as pesquisas experimentais (8,6\%), como apresentado na Figura 2.

Figura 2 - Procedimentos Técnicos dos Artigos

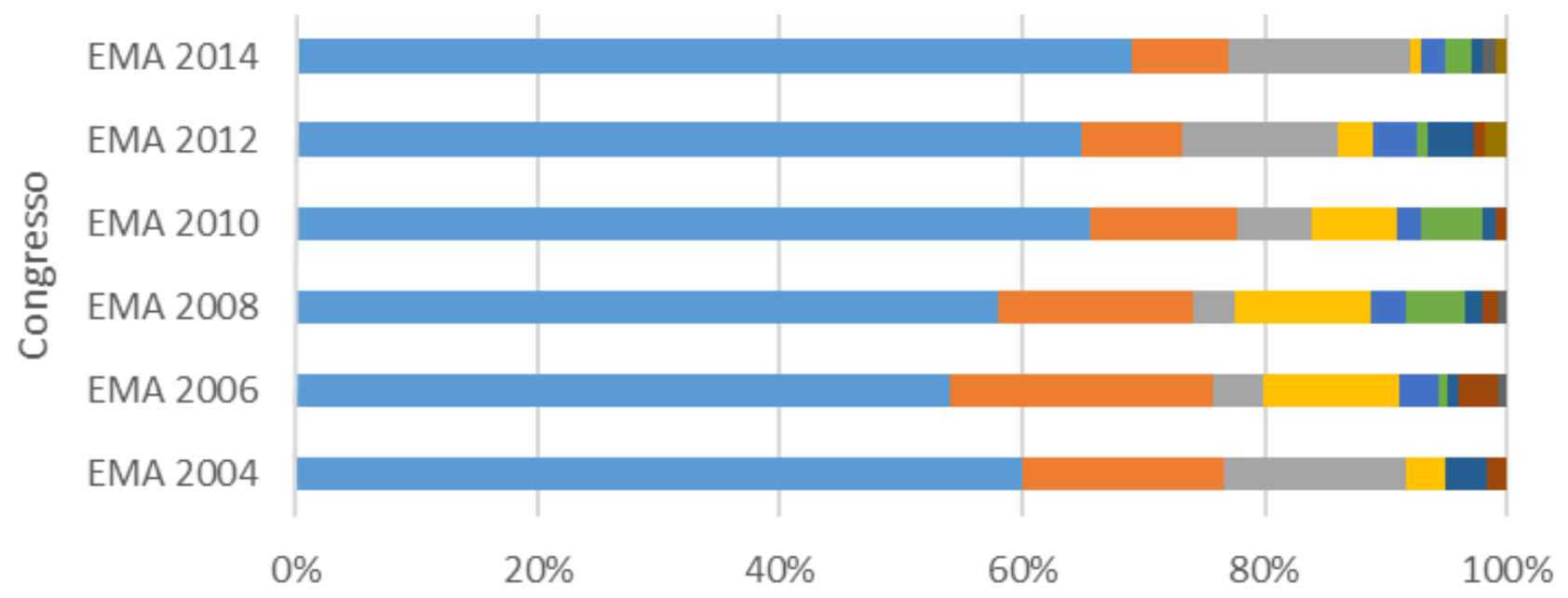
Levantamento de Campo @ Pesquisa bibliográfica
Pesquisa experimental
Estudo de Caso
Pesquisa bibliométrica
Pesquisa documental
Grupo em Foco

\section{Pesquisa etnográfica}
Meta-Análise

\section{Netnográfico}

Fonte: autores.

Quanto ao perfil das amostras utilizadas nos estudos apresentados, nota-se concentração na análise de consumidores ( $n=224 ; 35,4 \%)$. As amostras de consumidores são bastante diversifi- 
cadas, abarcando indivíduos de ambos os gêneros, desde adolescentes até idosos, torcedores de time de futebol, as crianças e pessoas com deficiência física e visual.

As empresas também figuram como amostras importantes para a pesquisa de Marketing nacional, com um total de 114 trabalhos (18\%). O acesso foi feito por meio da entrevista com funcionários, CEOs, gestores e empresários. Outra fonte de dados importante são os estudantes universitários ( $n=99 ; 15,6 \%)$ e os estudantes de cursos de pós-graduação $(n=15 ; 2,4 \%)$. Poucos trabalhos na área utilizam bases de dados secundários ( $\mathrm{n}=$ $31 ; 4,9 \%)$.

Tabela 12 - Amostras adotadas nos artigos

\begin{tabular}{|c|c|c|c|}
\hline Amostra & $\mathbf{N}$ & $\%$ & $\%$ acumulado \\
\hline Consumidores & 224 & 35,4 & 35,4 \\
\hline Empresas & 114 & 18,0 & 53,4 \\
\hline Universitários & 99 & 15,6 & 69,0 \\
\hline Base de Dados secundários & 31 & 4,9 & 73,9 \\
\hline Internautas (sites e rede social) & 21 & 3,3 & 77,3 \\
\hline Pós-Graduandos & 15 & 2,4 & 79,6 \\
\hline Alunos Ensino Médio & 5 & 0,8 & 80,4 \\
\hline Especialistas de áreas & 5 & 0,8 & 81,2 \\
\hline Docentes & 3 & 0,5 & 81,7 \\
\hline Outros & 116 & 18,3 & 100,0 \\
\hline Total & 633 & 100,0 & \\
\hline
\end{tabular}

Fonte: autores.

No total, na análise dos trabalhos dos Anais do Ema, existem 753 menções aos tipos de técnicas de análise de dados empregadas (Tabela 13). Nas pesquisas qualitativas, as técnicas de análise de dados mais utilizadas são a análise de conteúdo $(n=137 ; 18,2 \%)$, a análise documental $(n=27$; $3,6 \%)$ e a análise do discurso $(n=13 ; 1,7 \%)$. Já nas pesquisas quantitativas, a análise fatorial explorató- ria $(n=137 ; 18,2 \%)$, as regressões $(n=54 ; 7,2 \%)$ e a modelagem de equações estruturais ( $n=53 ; 7,2 \%)$ foram as técnicas de análise de dados preferidas.

A estatística descritiva, que está presente em trabalhos quantitativos e qualitativos, foi utilizada em 144 artigos (19,1\%). O detalhamento das opções de análise é apresentado na Tabela 13.

Tabela 13 - Técnicas de Análises utilizadas nos artigos

\begin{tabular}{lccc}
\multicolumn{1}{c}{ Técnica de análise de dados } & $\mathbf{n}$ & $\%$ & $\%$ acumulado \\
Estatística Descritiva & 144 & $19.1 \%$ & $19.1 \%$ \\
\hline Análise de Conteúdo & 137 & $18.2 \%$ & $37.3 \%$ \\
\hline Análise Fatorial Exploratória & 110 & $14.6 \%$ & $51.9 \%$ \\
\hline
\end{tabular}




\begin{tabular}{lccc}
\hline Regressão & 54 & $7.2 \%$ & $59.1 \%$ \\
\hline Modelagem de Equação Estrutural & 53 & $7.0 \%$ & $66.1 \%$ \\
\hline Análise Fatorial Confirmatória & 47 & $6.2 \%$ & $72.4 \%$ \\
\hline ANOVA & 45 & $6.0 \%$ & $78.4 \%$ \\
\hline Análise Documental & 27 & $3.6 \%$ & $81.9 \%$ \\
\hline Análise de Cluster & 20 & $2.7 \%$ & $84.6 \%$ \\
\hline Análise de Discurso & 13 & $1.7 \%$ & $86.3 \%$ \\
\hline MANOVA & 6 & $0.8 \%$ & $87.1 \%$ \\
\hline Análise Discriminante & 4 & $0.5 \%$ & $87.6 \%$ \\
\hline ANCOVA & 4 & $0.5 \%$ & $88.2 \%$ \\
\hline Outros testes estatísticos & 89 & $11.8 \%$ & $100.0 \%$ \\
\hline Total & 753 & $100.0 \%$ & \\
\hline
\end{tabular}

Fonte: autores.

\subsection{ANÁLISE DAS CITAÇÕES}

Os 633 artigos publicados nas seis edições do Encontro de Marketing da ANPAD apresentam um total de 22.907 referências bibliográficas. Com isso, observa-se uma média de 36,2 referências por artigo publicado.

Curiosamente, a edição de 2014 foi a que apresentou menor quantidade média de referên- cias (28,9 por artigo), contudo não é possível afirmar que isso seja uma tendência.

As 22.907 referências bibliográficas apresentadas referem-se a 12.142 trabalhos únicos, quer sejam artigos científicos, livros, websites, notícias de revistas e jornal, entre outros. A Tabela 14 apresenta os trabalhos internacionais mais citados.

Tabela 14 - Referências bibliográficas internacionais mais citadas

\begin{tabular}{llcc}
\multicolumn{1}{c}{ Autores } & \multicolumn{1}{c}{ Título } & $\begin{array}{c}\text { Citações } \\
\text { Kotler (2000) }\end{array}$ & $\begin{array}{c}\text { Média de citações } \\
\text { por congresso }\end{array}$ \\
\hline Malhotra (2001) & Pesquisa de Marketing (Livro) & 208 & 34,7 \\
\hline Aaker, Kumar e Day (2001) & Pesquisa de Marketing (Livro) & 166 & 27,7 \\
\hline Hair et al. (1995/1998) & Multivariate data analysis (Livro) & 122 & 20,3 \\
\hline Oliver (1980) & $\begin{array}{l}\text { A Cognitive Model of the Antecedents and } \\
\text { Consequences of Satisfaction Decisions }\end{array}$ & 102 & 17,0 \\
\hline $\begin{array}{l}\text { Parasuraman, Zeithaml e } \\
\text { Barry (1985) }\end{array}$ & $\begin{array}{l}\text { A conceptual model of Service Quality: Its } \\
\text { implications for future research }\end{array}$ & 101 & 16,8 \\
\hline $\begin{array}{l}\text { Sheth, Mittal e Newman } \\
\text { (2001) }\end{array}$ & $\begin{array}{l}\text { Comportamento do cliente - indo além do } \\
\text { comportamento do consumidor (Livro) }\end{array}$ & 82 & 13,7 \\
\hline & $\begin{array}{l}\text { Consumer Perception of Price, Quality } \\
\text { Zeithaml (1988) }\end{array}$ & 79 & 13,2 \\
\hline
\end{tabular}




\begin{tabular}{llcc}
\hline Belk (1988) & Possessions and the extended self & 76 & 12,7 \\
\hline Bagozzi, Yi e Phillips (1991) & $\begin{array}{l}\text { Assessing Construct Validity in } \\
\text { Organizational Research }\end{array}$ & 66 & 11,0 \\
\hline
\end{tabular}

Fonte: autores.

Das 10 referências bibliográficas internacionais mais citadas, quatro são livros traduzidos para o português e um livro em inglês, Apenas o livro mais citado é teórico [Administração de Marketing - Kotler (2000)], referenciado em média 34,7 vezes por edição do congresso. Os outros quatro livros são de métodos de pesquisa e análise de dados. O artigo científico mais citado é o célebre trabalho " $A$ congnitive model of the antecedentes and consequences of satisfaction decisions" de Oliver (1980). Ressalta-se que, em média, as dez referências mais citadas foram utilizadas 112 vezes pelos acadêmicos que publicaram no EMA.

Assim como nas referências internacionais, quando se analisam as referências feitas dos trabalhos nacionais, percebe-se a grande utilização de livros. As duas referências mais citadas são livros de método (Silvia Vergara e Antonio Carlos Gil), e a terceira é o livro sobre administração varejista de Juracy Parente, citado 20 vezes nos anais do EMA.

O artigo teórico mais citado (18 vezes) é o trabalho de Santos e Rossi (2002) (O impacto do gerenciamento de reclamações na confiança e na lealdade do consumidor). Destaca-se também uma única tese de doutoramento entre as referências mais utilizadas (A avaliação do relacionamento sob a ótica do cliente: um estudo em bancos de varejo, de Paulo Henrique Muller Prado). Estes dados podem ser observados em detalhe na Tabela 15.

Tabela 15 -Referências bibliográficas nacionais mais citadas

\begin{tabular}{|c|c|c|c|}
\hline Autores & Título & Citações & $\begin{array}{c}\text { Média de Citações por } \\
\text { Congresso }\end{array}$ \\
\hline Parente (2000) & Varejo no Brasil (Livro) & 20 & 3,3 \\
\hline Mattar (1999) & Pesquisa de Marketing (Livro) & 16 & 2,7 \\
\hline
\end{tabular}




\begin{tabular}{llcc}
\hline $\begin{array}{l}\text { Rossi e Slongo } \\
(1998)\end{array}$ & $\begin{array}{l}\text { Pesquisa de Satisfação de Clientes: o Estado- } \\
\text { da-Arte e Proposição de um Método Brasileiro }\end{array}$ & 15 & 2,5 \\
\hline Prado (2004) & $\begin{array}{l}\text { A avaliação do relacionamento sob a ótica do } \\
\text { cliente: um estudo em bancos de varejo (Tese) }\end{array}$ & 9 & 1,5 \\
\hline $\begin{array}{l}\text { Perin e Sampaio } \\
(2003)\end{array}$ & $\begin{array}{l}\text { Orientação para o Mercado, Porte Empresarial } \\
\text { e Performance: um estudo longitudinal no setor } \\
\text { Eletroeletrônico do Brasil }\end{array}$ & 8 \\
\hline Farias (2002) & $\begin{array}{l}\text { Pesquisa Flexível em Marketing: o Lado } \\
\text { Humanista de uma Ciência Socialmente } \\
\text { Construída e Fixamente Investigada }\end{array}$ & 8 \\
\hline \multirow{2}{*}{ Brei e Rossi (2002) } & $\begin{array}{l}\text { Confiança, Valor Percebido e Lealdade em } \\
\text { Trocas Relacionais de Serviços: Um Estudo com } \\
\text { Usuários de Internet Banking no Brasil }\end{array}$ & \multirow{2}{*}{6} \\
\hline
\end{tabular}

Destaca-se que, no entanto, a média de citações das referências nacionais é muito menor que as citações relativas aos trabalhos internacionais $\left(\mathrm{M}_{\text {nacional }}=14\right.$ vezes versus $\mathrm{M}_{\text {internacional }}=112$ vezes $)$. Com isso, é possível afirmar que os acadêmicos de Marketing no Brasil pouco utilizam trabalhos de seus pares em suas pesquisas científicas.

Finalmente, conduziu-se a AFE da matriz de cocitações. Para essa etapa, utilizou-se a matriz organizada por autores. A amostra mostrou-se adequada para o uso dessa técnica estatística, pois apresentou o indicador KMO (Kaiser-Meyer-Olkin)
$=0,951$ e teste de esfericidade de Bartlett significativo ao nível de 1\% $\left(\square^{2}=39264,52 ; 3240 \mathrm{gl}\right.$; $p<0,001)$.

Após várias etapas de refinamento do modelo, no qual se buscou identificar comunalidades $\left(h^{2}\right)$ e cargas fatoriais superiores a 0,50, além cargas cruzadas inferiores a 0,40 (LEVIN; FOX, 2005), encontrou-se a solução fatorial mais adequada. Identificou-se quatro fatores com autovalor superior a 1, que explicaram $64,1 \%$ da variância total da amostra, com a identificação de 60 autores. 0 resultado dessa fase é apresentado na Tabela 16. 
Tabela 16 - Análise fatorial exploratória da matriz de citações

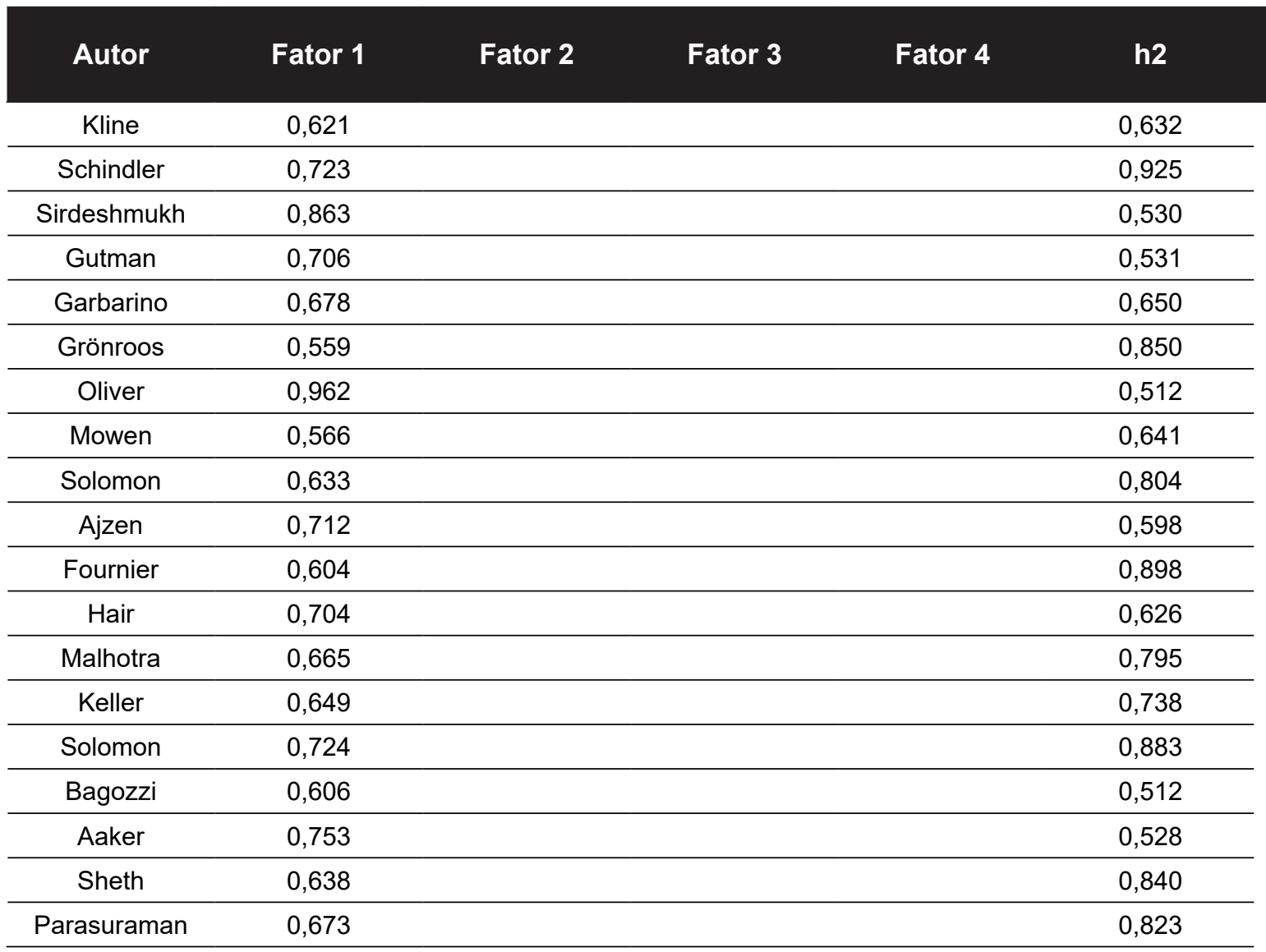

Variância

Explicada 


\begin{tabular}{|c|c|c|c|c|c|c|}
\hline Autor & Fator 1 & Fator 2 & Fator 3 & Fator 4 & h2 & $\begin{array}{l}\text { Variância } \\
\text { Explicada }\end{array}$ \\
\hline Belk & & 0,800 & & & 0,625 & \multirow{24}{*}{$17,10 \%$} \\
\hline Foucault & & 0,778 & & & 0,791 & \\
\hline Gil & & 0,728 & & & 0,730 & \\
\hline Moorman & & 0,793 & & & 0,925 & \\
\hline Sheth & & 0,632 & & & 0,547 & \\
\hline Lipovetsky & & 0,734 & & & 0,555 & \\
\hline Bearden & & 0,672 & & & 0,887 & \\
\hline Kapferer & & 0,749 & & & 0,524 & \\
\hline Baudrillard & & 0,664 & & & 0,878 & \\
\hline Lovelock & & 0,859 & & & 0,941 & \\
\hline Vergara & & 0,566 & & & 0,534 & \\
\hline Yin & & 0,690 & & & 0,925 & \\
\hline Baker & & 0,738 & & & 0,669 & \\
\hline Hooley & & 0,766 & & & 0,892 & \\
\hline Blackwell & & 0,746 & & & 0,737 & \\
\hline Hunt & & 0,914 & & & 0,530 & \\
\hline Morgan & & 0,953 & & & 0,869 & \\
\hline Engel & & 0,575 & & & 0,701 & \\
\hline Churchill & & 0,674 & & & 0,972 & \\
\hline Hunt & & 0,762 & & & 0,579 & \\
\hline Bardin & & 0,876 & & & 0,546 & \\
\hline Holbrook & & 0,592 & & & 0,737 & \\
\hline Belk & & 0,849 & & & 0,786 & \\
\hline Baudrillard & & 0,700 & & & 0,784 & \\
\hline Prahalad & & & 0,890 & & 0,565 & \multirow{10}{*}{$12,60 \%$} \\
\hline Engel & & & 0,516 & & 0,967 & \\
\hline Mattar & & & 0,983 & & 0,675 & \\
\hline Porter & & & 0,546 & & 0,543 & \\
\hline Prado & & & 0,767 & & 0,744 & \\
\hline Mccracken & & & 0,985 & & 0,579 & \\
\hline Parente & & & 0,727 & & 0,529 & \\
\hline Perin & & & 0,625 & & 0,585 & \\
\hline Schiffman & & & 0,903 & & 0,514 & \\
\hline Fornell & & & 0,742 & & 0,651 & \\
\hline Cronin & & & & 0,830 & 0,841 & \multirow{7}{*}{$9,94 \%$} \\
\hline Brown & & & & 0,646 & 0,543 & \\
\hline Day & & & & 0,780 & 0,807 & \\
\hline Reichheld & & & & 0,912 & 0,622 & \\
\hline Berry & & & & 0,589 & 0,848 & \\
\hline Kotler & & & & 0,788 & 0,542 & \\
\hline Zeithaml & & & & 0,541 & 0,525 & \\
\hline
\end{tabular}

Fonte: autores. 
O fator 1 , que responde por $24,5 \%$ da variância total explicada, agrupou os autores clássicos de consumer psychology e consumer behavior, além de autores de métodos de análise quantitativa de dados e pesquisa de Marketing.

O fator 2 (17,1\% da variância explicada) agrupou os autores de trabalhos sobre metodologia qualitativa de análise de dados, autores que focam seus trabalhos em estudos teóricos e exploratórios e alguns que militam em consumer culture theory.

O terceiro fator $(12,6 \%$ da variância total) agrupou os autores de estratégias de marketing e administração estratégica geral. Finalmente, o quarto fator (9,94\% da variância explicada) agrupou alguns autores de Marketing geral e serviços.

Aparentemente, essas são as principais correntes teóricas que norteiam as pesquisas em Marketing no Brasil.

\section{DISCUSSÃO DOS RESULTADOS}

Algumas fragilidades da pesquisa em Marketing no Brasil ficam visíveis por meio da análise dos dados deste levantamento. Para atingirmos a tão sonhada internacionalização, algumas deficiências precisam ser atacadas pelos pesquisadores da área.

Inicialmente, cita-se a necessidade de meIhoria da relevância teórica dos estudos apresentados no principal congresso de Marketing brasileiro. A baixa sinergia entre pesquisadores e a falta de formação de grupos de pesquisa consistentes podem ser consideradas motivos para explicar o pouco avanço teórico proposto nos trabalhos de Marketing. Diferentemente de outras áreas, nas quais é natural vermos a autoria de trabalhos aca- dêmicos ser dividida por seis ou mais pesquisadores (veja, por exemplo: BAQUIÃO et al., 2013 na Biologia ou MORAIS et al., 2015, da área de Química), nos estudos de Marketing há concentração na dupla autoria (40\%) e nos trabalhos assinados por três pesquisadores $(29,1 \%)$.

O baixo investimento das instituições de ensino privado em pesquisa também é um obstáculo para a melhoria da qualidade da pesquisa científica. Tendo em vista que $88 \%$ das instituições de ensino brasileiras são privadas (MEC, 2013), deveríamos ter mais instituições dessa natureza no ranking de produtividade do evento.

A qualidade das referências bibliográficas utilizadas também pode ser um ponto de alerta. Um livro utilizado no nível de graduação ser a referência mais citada no principal congresso de Marketing do Brasil causa certa estranheza. Certamente, o avanço teórico e científico almejado deve ter como base os principais artigos científicos dos periódicos de maior impacto, tanto nacionais quanto internacionais. Alia-se a esse fato o baixo número de citação de trabalhos acadêmicos nacionais. Provavelmente, esse fenômeno está relacionado com a baixa produção científica em inglês. Evidentemente, a publicação de papers em inglês potencializaria as citações.

Finalmente, a relativa endogenia das fontes teóricas pode representar um risco para o avanço da qualidade dos trabalhos de Marketing. Apenas 60 autores responderam por mais de $64 \%$ da variância explicada da matriz de citações de todos os trabalhos publicados nas seis edições do EMA. Mesmo que esses autores sejam expoentes em áreas relevantes da pesquisa em Marketing (consumer psychology, consumer behavior, consu- 
mer culture theory e Marketing de Serviços), pode ser que esse plantel não seja suficiente para "arejar" e inspirar as mentes nacionais na busca pelo avanço científico.

De qualquer modo, o Encontro de Marketing da ANPAD tem buscado sua consolidação, além de ser uma das grandes ferramentas da academia, visando aumentar o intercâmbio de ideias, a discussão crítica de trabalhos científicos e a valorização dos pesquisadores de Marketing no Brasil.

Em suas seis edições, o EMA serviu de palco para que mais de 600 trabalhos fossem apresentados e tivessem a oportunidade de serem debatidos. Certamente, vários autores desses trabalhos receberam sugestões de melhorias e recomendações para o desenvolvimento de seus papers, com o objetivo de lograrem uma publicação em caráter definitivo.

Ressalta-se a importância do incentivo das instituições de ensino superior no sentido de prestigiarem seus pesquisadores e, muitas vezes, fomentarem a participação desses nos congressos científicos.

Ressalta-se também a relevância da comunidade de pesquisadores de Marketing na figura dos Profs. Fernando Bins Luce e Carlos Alberto Vargas Rossi, que com perseverança e empenho conseguiram estruturar o Encontro de Marketing da ANPAD e mantê-lo na última década. Ademais, um aspecto que ficou latente durante a realização deste trabaIho foi o sentido de inovação e desenvolvimento que o congresso apresenta ano após ano.

\section{LIMITES, SUGESTÕES E CONSIDERAÇÕES FINAIS}

Acreditamos que o objetivo central do presente estudo foi atingido. Após extenso levanta- mento de dados, classificação dos artigos e análise dos dados, entende-se que as principais características do Encontro de Marketing da ANPAD tenham ficado evidenciadas. Contudo, vários limites cercaram este trabalho.

Inicialmente, algumas análises poderiam ter sido realizadas sob a perspectiva temporal, evitando-se algumas dúvidas futuras. Por exemplo: será que a endogenia das citações está reduzindo com o avanço dos encontros? Será que a distribuição dos trabalhos pelas áreas temáticas está em processo de mudança? Infelizmente, não conseguimos responder a essas questões. Com isso, sugere-se que estudos futuros analisem as mudanças que estão acontecendo com o passar do tempo e a consolidação do evento.

Do mesmo modo, seria interessante conhecer o destino final dos artigos apresentados no EMA, com o objetivo de verificar quantos se tornam artigos de periódico. Nesse sentido, propõe-se nossa segunda sugestão de estudos futuros.

Seria também uma contribuição para a continuidade dessa agenda de pesquisa entender até que ponto realmente é um diferencial publicar um trabaIho em inglês para o congresso, visto que os poucos artigos nessa situação não estão entre os mais citados.

Finalmente, reforça-se que uma das motivações que levaram à realização deste estudo foi o desejo de presenciar a consolidação da pesquisa de Marketing no Brasil e também testemunhar o estabelecimento de seu posicionamento na academia mundial. De certo, o EMA tem contribuído para esse objetivo, porém muito ainda precisa ser feito para que esse sonho se torne realidade. Nesse sentido, espera-se que o presente trabalho tenha contribuído para esse fim. 


\section{REFERÊNCIAS}

AMA - American Marketing Association, Disponível em: https://www.ama.org/Pages/default. aspx. Acesso em: 18 fev. 2016.

BAQUIÃO, Arianne Costa et al. Optimized nested polymerase chain reaction for antemortem detection of mycobacteria in amazon parrots (amazona aestiva) and orange-winged Amazons (Amazona Amazonica). Journal of Zoo and Wildlife Medicine, v. 45, n. 1, p. 161-164, 2014.

BRENNAN, Ross. Should we worry about an "academic-practitioner divide" in marketing?. Marketing Intelligence \& Planning, v. 22, n. 5, p. 492-500, 2004.

CARDOSO, Ricardo Lopes et al. Pesquisa científica em contabilidade entre 1990 e 2003. RAE-revista de administração de empresas, v. 45, n. 2 , p. 34-45, 2005.

FARIA, Alexandre. Em busca de relevância no âmbito de estratégia de marketing. In: ENCONTRO NACIONAL DOS PROGRAMAS DE PÓS-GRADUAÇÃO EM ADMINISTRAÇÃO. Anais [...]. 2004.

LACERDA, José Edson Lara. Mapeamento, análise e classificação dos trabalhos acadêmicos de Marketing nos Enanpads de 2000 a 2005. 2006.

GARRAFA, Volnei. Reflexões bioéticas sobre ciência, saúde e cidadania. Bioética, v. 7, n. 1, p. 13-20, 1999.

HAIR, Joseph F. el al. Multivariate data analysis (Vol. 6). Upper Saddle River, NJ: Pearson Prentice Hall, 2006.
KOVACS, Michelle Helena et al. Podemos confiar nos resultados de nossas pesquisas? Uma avaliação dos procedimentos metodológicos nos artigos de marketing do EnANPAD. In: ENCONTRO DE MARKETING DA ANPAD, 2004.

LEVIN, Jack; FOX, J. A. Elementary statistics in social research. Pearson Education India, 2005.

MAZZON, José Afonso; HERNANDEZ, José Mauro da Costa. Produção científica brasileira em marketing no período 2000-2009. Revista de Administração de Empresas, v. 53, n. 1, p. 67, 2013.

MEC. Panorama e diagnóstico da oferta e qualidade da Educação Superior brasileira. Documento técnico. Disponível em: http://portal.mec.gov. br/index.php?option=com_docman\&view=download\&alias=13944-produto-1 -senso-educ-superior-pdf\&category_slug=setembro-2013-pdf\&ltemid=30192. Acesso em: 02 fev. 2016.

HANSOTIA, Behram J. Bridging the research gap between marketing academics and practitioners. Journal of Database Marketing \& Customer Strategy Management, v. 11, n. 2, p. 114-120, 2003.

HUNT, Shelby D. Marketing as a profession: on closing stakeholder gaps. European Journal of Marketing, v. 36, n. 3, p. 305-312, 2002.

RICHERS, Raimar. Recordando a infância do marketing brasileiro-um depoimento. Revista de Administração de Empresas, v. 34, n. 3, p. 26-40, 1994. 


\section{REFERÊNCIAS}

SPLITTER, Karla; ROSA, C. A.; BORBA, José Alonso. Uma Análise das Características dos Trabalhos "Ditos" Bibliométricos Publicados no Enanpad entre 2000 e 2011. In: ENCONTRO DA ASSOCIAÇÃO NACIONAL DE PÓS-GRADUAÇÃO E PESQUISAS EM ADMINISTRAÇÃO. Anais [...]. v. 36, 2012.

PRINGLE, Lewis G. The Academy and The Practice: In Principle, Theory and Practice Are Different. But, in Practice, They Never Are. Marketing Science, v. 20, n. 4, p. 373-381, 2001.

QUINTÃO, Ronan Torres et al. A literatura das disciplinas de marketing em doutorados no Brasil e nos Estados Unidos: descrição e reflexões. In: ENCONTRO ANUAL DA ASSOCIAÇÃO NACIONAL DOS PROGRAMAS DE PÓS-GRADUAÇÃO EM ADMINISTRAÇÃo, v. 35, 2011.
VIEIRA, Francisco GD. Panorama acadêmico-científico e temáticas de estudos de marketing no Brasil. In: ENCONTRO NACIONAL DE PROGRAMAS DE PÓS-GRADUAÇÃO EM ADMINISTRAÇÃO. Anais [...]. Florianópolis: Anpad, 2000.

VIEIRA, Ricardo S. Gomes et al. O Conhecimento do marketing sob os olhos da teoria crítica. In: ENCONTRO DA ASSOCIAÇÃO NACIONAL DE PÓS-GRADUAÇÃO E PESQUISA EM ADMINISTRAÇÃO. Anais [...]. v. 26, 2002. 